\title{
Al-density variation as one driving force for void formation in PERC solar cells
}

\author{
Renate Horbelt" ${ }^{*}$, Stefanie Ebert', Vaidvile Ulbikaite', Giso Hahn', Reinhart Job², \\ and Barbara Terheiden ${ }^{1}$ \\ ${ }^{1}$ Department of Physics, University of Konstanz, 78457 Konstanz, Germany \\ ${ }^{2}$ Department of Electrical Engineering and Computer Science, Muenster University of Applied Sciences, 48565 Steinfurt, Germany
}

Keywords Al paste, Si, Kirkendall effect, passivated emitter rear contact, PERC, solar cells, void

${ }^{*}$ Corresponding author: e-mail renate.horbelt@uni-konstanz.de, Phone: +49 753188 2079, Fax: +49 7531883895

The reduction of void formation in local $\mathrm{Al}$ contact structures is of high interest in studies dealing with passivated emitter and rear contact (PERC) solar cells. So far, several processing parameters and their impact on local contact formation were investigated in detail. However, up to now density variation of $\mathrm{Al}$ in dependence on temperature and Si content in the melt were not taken into account as a principal reason for void formation. In this context the current assumption of a constant volume of the $\mathrm{Al}$ paste particles is discussed in more detail. Based on the results of energy dispersive X-ray spectroscopy, void formation implies either an expansion of paste particles or their burst during contact formation.

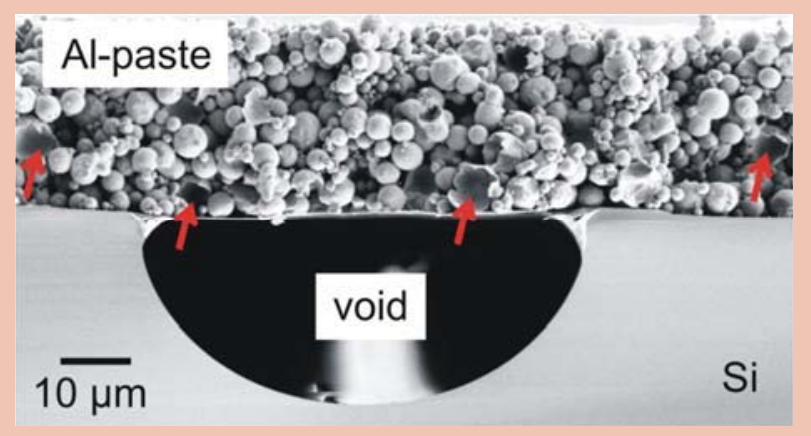

1 Introduction So far, the passivated emitter and rear contact (PERC) cell, first introduced by Blakers et al. [1], is one of the most intensely investigated silicon solar cell concepts. Among other things it is characterized by a locally opened dielectric passivation layer on the rear side, resulting in very low surface recombination velocity, high internal reflectivity, and local Al contact formation. An ideally formed local contact is filled with an $\mathrm{Al} / \mathrm{Si}$ eutectic and features a homogeneously formed local back surface field (LBSF), responsible for the passivation of the local contact area. Under certain conditions the eutectic is missing and the so-called "voids" are formed (see Fig. 4). These "voids" were observed first and investigated in more detail by Urrejola et al. [2]. Previous studies concerning void formation dealt e.g. with the impact of contact geometry and contact opening technique, paste composition, firing conditions and post laser treatment [3-12]. Additionally, an insufficient surface wetting during contact formation process has been discussed as an essential origin of void formation $[13,14]$.

Within this work for the first time the $\mathrm{Al}$ contact formation and in particular the void formation are traced back to the density variation of an Al melt and its corresponding volume variation [15] and stress relief mechanisms of Al-Si alloy particles involving a creep or cracking of particles as described in [16], whereas the extent of volume variation depends on the temperature and the $\mathrm{Si}$ content in the melt.

Based on these findings some discrepancies in established theses concerning void formation are discussed. Additionally, the results of scanning electron microscopy (SEM) and energy dispersive X-ray spectroscopy (EDX) 
on characteristic voids are implemented in a new working hypothesis concerning void formation.

2 Variation of Al density with temperature and Si content A density value of $2.7 \mathrm{~g} / \mathrm{cm}^{3}$ is found in literature for solid $\mathrm{Al}$ at room temperature. However, during co-firing in the solar cell fabrication process the melting point of pure $\mathrm{Al}\left(T_{\text {melt }}=660{ }^{\circ} \mathrm{C}\right)$ is exceeded significantly reaching peak temperatures $T_{\text {peak }}$ in the range of 750 to $880{ }^{\circ} \mathrm{C}$. Schmitz et al. investigated the density variation of an $\mathrm{Al}$ melt in dependence of Si content $(0-50 \%)$ and temperature [15]. In this section the experimental results of Schmitz et al. are discussed.

For the Al melt a considerable drop in density is given with increasing temperature, generating an increase of volume (in the following termed as "volume effect"). For pure Al a density of $2.36 \mathrm{~g} / \mathrm{cm}^{3}$ at $750{ }^{\circ} \mathrm{C}$ is estimated from Fig. 1 in [15]. This corresponds to a reduction of density during transition from solid phase to melt of $0.34 \mathrm{~g} / \mathrm{cm}^{3}$, i.e. an increase of volume of $12.6 \%$.

However, no pure $\mathrm{Al}$ is involved in the contact formation process, as - according to the $\mathrm{Al} / \mathrm{Si}$ phase diagram of Murray et al. - the Si content in the melt increases with temperature [17]. Assuming a Si content of $20 \%$ in the melt, a density of $2.44 \mathrm{~g} / \mathrm{cm}^{3}$ is estimated at a constant temperature of $750{ }^{\circ} \mathrm{C}$ (Fig. 1 in [15]). Hence, the drop in density i.e. the "volume effect" is reduced by a higher Si content in the melt at the same temperature. Until reaching $T_{\text {peak }}$, density reduction is lowered by simultaneous increase of $\mathrm{Si}$ content in the melt, as described by the $\mathrm{Al} / \mathrm{Si}$ phase diagram. However, at $T_{\text {peak }}$ the melt is characterized by the lowest density value during the contact formation process, maximizing the "volume effect".

The data of Schmitz et al. give an additional aspect for a phenomenon observed in several studies: a reduction of void formation was achieved by adding $\mathrm{Si}$ to the original paste $[6,18,19]$. So far, only the effect of the reduced Si concentration gradient between $\mathrm{Si}$ and Al-paste leading to a lower amount of $\mathrm{Si}$, dissolving in the $\mathrm{Al} / \mathrm{Si}$ melt, is taken into account. However it does not explain why the voids nevertheless form.

Here the aforementioned reduction of the "volume effect" from solid phase to liquid phase, and vice versa, due to higher Si content in the paste matrix comes into play and acts as an additional explanation. However, a Si content in the paste higher than $12 \%$ increases the paste resistivity significantly [20] and has to be avoided.

3 Stress-relief mechanisms of Al-Si alloy particles Storaska et al. demonstrated in their study, that high stress, caused by the expanding melt in the paste particle, lead to a uniform creek of the oxide shell [16]. This creek balances the volume increase due to density variation by melting of an Al-alloy. However, if the oxide shell contains defects (e.g. thinner oxide), the stress will lead to a crack at these weakened spots, resulting in a partially ejection of the liquid melt of the paste particles. Small drops nearby the particle have been indicated by Storoska et al. using in-situ electron microscopy measurements.

To the authors' knowledge, so far these results of Stroroska et al. have been not discussed with respect to void formation.

4 Void formation - discrepancies in established hypotheses Urrejola et al. explained the formation of voids by the "Kirkendall effect", which is based on a differing diffusivity of the involved atoms [2]. The classical experiment refers to solid diffusion solely [21], which is not given during contact formation process. However, liquids show different diffusivities as well, forming pores (diffusion porosity) due to condensed excess vacancies which are not compensated by the liquid flow. In literature these voids are termed as another characteristic for the Kirkendall effect $[22,23]$. Discussing void formation in PV, it has to be carefully distinguished, which phenomenon is the appropriate one.

So far, a constant volume of the Al paste particles is expected during the complete contact formation process $[24,25]$. It was argued that shape and volume of the single paste particles were kept stable by a thin surrounding oxide shell. Furthermore, it was assumed that the dissolved Si of the local contact areas is incorporated in the Al paste particles $[25,26]$. However, as shown in Section 3 of this work, a constant particle volume requires that during heating up the expanding $\mathrm{Al}$ requires that either the paste particles themselves expand to cover the Al with its larger volume, or if the $\mathrm{AlO}_{x}$ shell breaks $\mathrm{Al}$ spills out of the particles forming new or larger Al particles. In all cases the paste matrix volume is increased, and only this allows generating the voids in the contact area where after cooldown $\mathrm{Si}$ and/or $\mathrm{Al} / \mathrm{Si}$ eutectic is missing.

It has to be emphasized that the density variation of $12.6 \%$ from solid to liquid state cracking the oxide shells can lead possibly to a complete spill out of the liquid melt out of the paste particles. The generated volume of empty paste particles enables a void ratio significantly higher than $12.6 \%$.

Urrejola stated that the missing $\mathrm{Si}$ in the contact area could be found in a thin layer beneath the $\mathrm{Al}$ paste matrix [18].

In the following the above mentioned topics will be discussed in more detail, focusing on the question of the disposition of $\mathrm{Al}$ and $\mathrm{Si}$ atoms after contact formation.

\section{Experimental results}

5.1 Sample configuration The local Al contacts under investigation are found in standard PERC type solar cells $(170 \mu \mathrm{m}$ thick p-type $\mathrm{Cz}-\mathrm{Si}$ with specific resistivity of $2-3 \Omega \mathrm{cm})$. The solar cells feature a homogeneous $\mathrm{n}^{+}$ emitter on the front side $\left(R_{\text {sheet }}=60 \Omega / \mathrm{sq}\right)$ passivated by a stack of thermally grown $\mathrm{SiO}_{2}$ and a $\mathrm{SiN}_{x}: \mathrm{H}$ layer grown via plasma enhanced chemical vapor deposition (PECVD). The dielectric stack on the rear side consists of an $\mathrm{Al}_{2} \mathrm{O}_{3}$ 
and a $\operatorname{SiN}_{x}: \mathrm{H}$ layer stack. The locally opened contact area has a width of $40 \mu \mathrm{m}$ directly after laser ablation (ps pulsed laser) and a pitch of $1.1 \mathrm{~mm}$. Front and rear side contacts were screen printed using commercially available $\mathrm{Ag}$ and $\mathrm{Al}$ pastes, respectively. Contact formation was carried out during a co-firing process in a belt furnace.

\subsection{Al, Si and Al/Si eutectic in local contacts In} general, application of scanning electron microscopy (SEM) allows investigating the different local contacts, as already shown by other authors [18, 27.]. Very detailed studies of about 220 local contacts by SEM demonstrated a reproducible void size and depth, depending on paste, contact geometry and temperature [28].

Within the current work a local contact, partially filled with eutectic (see Fig. 1) and a void (see Fig. 2) are investigated in more detail by energy dispersive X-ray spectroscopy (EDX). The aim is to determine where the Al from the paste particles that is replaced by Si can be found after contact formation.

The blue line in Fig. 1 symbolizes the LBSF of the "partially filled contact", which is not visible in form of a contrast variation in that image due to the choice of the detector. According to the binary $\mathrm{Al} / \mathrm{Si}$ phase diagram, the LBSF consists of epitaxially grown, Al-doped Si $(\beta-\mathrm{Si})$ with a maximum Al concentration of $0.016 \%$ [17]. Typically, the thickness of a LBSF is in the range of several micrometers. Both, the low Al content of the LBSF and its small thickness compared to the total contact depth indicate an insignificant amount of $\mathrm{Al}$ that is incorporated here compared to the amount of $\mathrm{Al}$ replaced by $\mathrm{Si}$ in the $\mathrm{Al}$ particles.

EDX measurements on the marked positions 1-3 in Fig. 1 disclose the composition of the material of such a partially filled contact. Measurement pos. 1 (columnar structure at the bottom) and measurement pos. 2 show a very high Al-concentration of 96 at $\%$ and 100 at $\%$, whereas the concentration of $\mathrm{Si}$ in pos. 1 is $1.4 \mathrm{at} \%$, that of $\mathrm{O}$ is 2.6 at $\%$.

The formation of such Al-rich structures is originated in the existence of a hypoeutectic melt in the contact area.

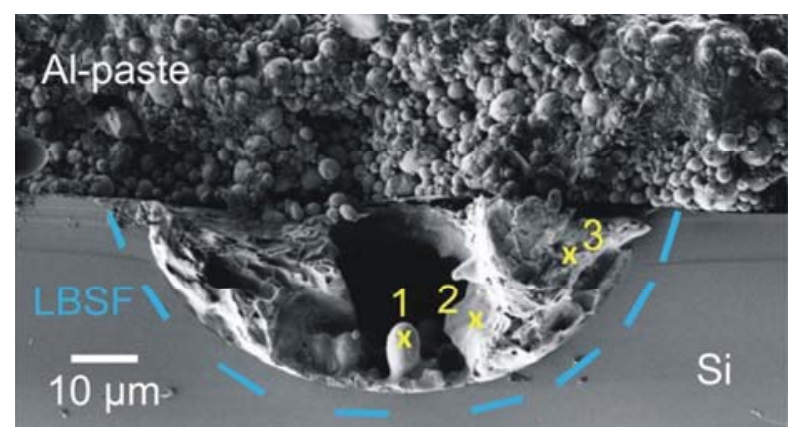

Figure 1 Contact partially filled with eutectic featuring columnar structures on the bottom. EDX measurements were carried out in the marked spots.

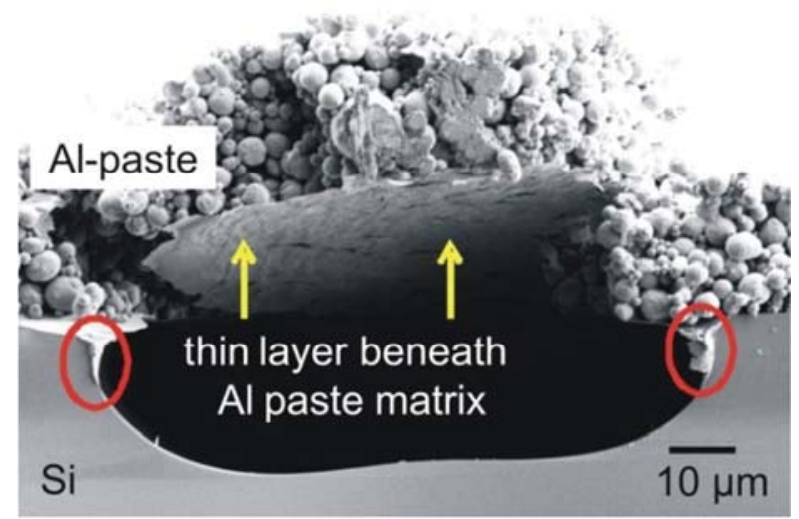

Figure 2 Cross-sectional view of a void, featuring a thin layer beneath the $\mathrm{Al}$ paste matrix. Some remaining eutectic is detectable at both edges of the void (red circles).

During cool-down, so called $\alpha$-Al primary crystals grow in the liquid melt [17]. According to the $\mathrm{Al} / \mathrm{Si}$ phase diagram, this Al-rich melt solidifies at higher temperature than the melt with a higher amount of $\mathrm{Si}$, as indicated in pos. $3(\mathrm{Al}=88$ at $\%, \mathrm{Si}=8.9$ at $\%, \mathrm{O}=3 \mathrm{at} \%)$. However, the volume of these Al-rich structures is too small to contain all $\mathrm{Al}$ atoms replaced by $\mathrm{Si}$ in the paste particles.

A second characteristic of voids is shown in Fig. 2. At both edges of the void, directly beneath the Al paste, voids feature some eutectic (red circles in Fig. 2). This phenomenon has been already shown by other authors [18, 27]. Once again, the small volume of this eutectic is not sufficient to incorporate all the $\mathrm{Al}$ atoms which are removed from the paste particles.

All investigated voids showed a thin layer beneath the Al paste matrix (see Fig. 2), which was not detectable at local contacts filled with an eutectic.

To determine the chemical composition of this thin layer, a freestanding layer (layer thickness of $100 \mathrm{~nm}$ to $150 \mathrm{~nm}$ ) was prepared by focused ion beam (FIB) and investigated by high resolution transmission electron microscopy (HRTEM). Figure 3 (left) shows the TEM image of that freestanding layer (top view) and the result of the corresponding spatially resolved EDX measurement (Fig. 3, right).
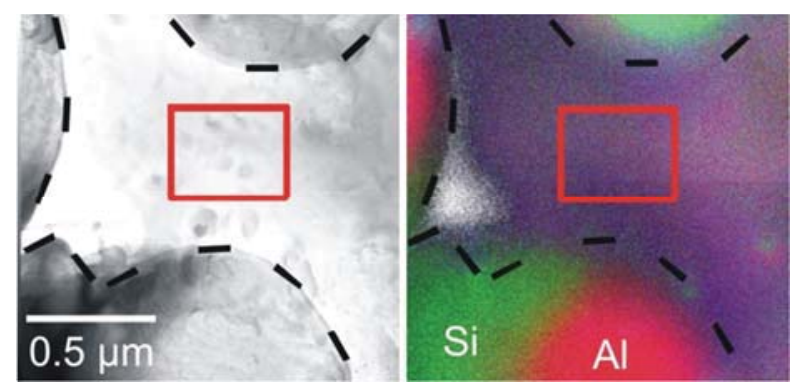

Figure 3 TEM image of a freestanding thin layer (top view) on the left. Remaining paste particles marked in black. The freestanding layer under investigation is marked in red. Right: corresponding spatially resolved EDX measurement. 


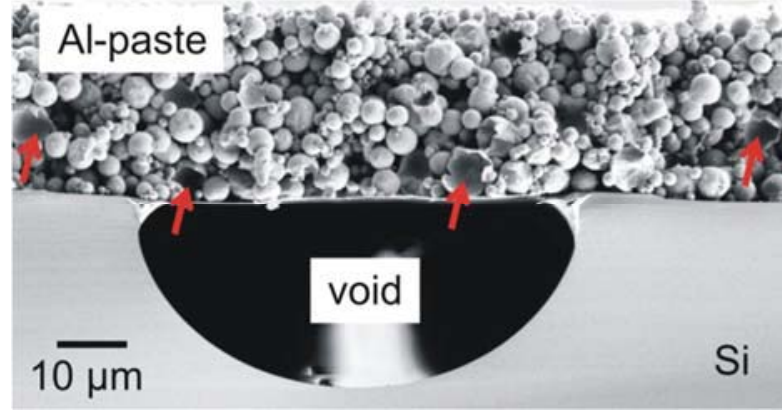

Figure 4 SEM image of an Al-paste matrix located directly above the void. The red arrows indicate some paste particles burst during contact formation.

An overlay of the signal intensities of $\mathrm{Al}$ (red), $\mathrm{Si}$ (green) and $\mathrm{O}$ (blue) shows a uniform distribution of these elements within the area under investigation (rectangle, marked in red). The dominating elements of the layer are Al (26 at \%), Si (7 at\%), and O (21.8 at\%). High amounts of $\mathrm{C}(13.5 \mathrm{at} \%) \mathrm{Ga}(10.9 \mathrm{at} \%) \mathrm{Cu}(16.1 \mathrm{at} \%)$ and other elements are originated in the sample preparation and the measurement set up. However, even if Al is the main component of the layer, a thickness of about $150 \mathrm{~nm}$ cannot contain a sufficiently high amount of $\mathrm{Al}$ atoms, replaced by $\mathrm{Si}$ in the paste particles. In contrast to Urrejola [18], this measurement demonstrates that the missing $\mathrm{Si}$ of the contact area is not located underneath the local contact. Großer et al. investigated such a thin layer in filled contacts and attributed it to an oxide layer (thickness $25 \mathrm{~nm}$ ) comparable to that of the paste particles [27].

Additionally, Fig. 3 (right) reveals an incorporation of $\mathrm{Si}$ in the remaining paste particles which is in good agreement with other studies, investigating the lateral diffusion of $\mathrm{Si}$ into the paste particles in more detail [29, 30].

Obviously, no significant incorporation of $\mathrm{Al}$ or $\mathrm{Si}$ takes place in $\alpha-\mathrm{Al}, \beta-\mathrm{Si}$ (LBSF), in the remaining eutectic within a void, or in the thin layer beneath the $\mathrm{Al}$ paste matrix. According to the studies of density variation, the volume of the paste particles needs to increase by about $10 \%$. This increase in volume of the $\mathrm{Al}$ paste particles is not detectable by SEM imaging since a measurement of one and the same paste particle before and directly after contact formation is technically not feasible. On the other hand, if the expansion of paste particles is restricted by the surrounding oxide layer, a burst of the particles is assumed. SEM images taken at voids (e.g. Fig. 4) give a first hint that this can occur during contact formation. The red arrows indicate some of the cracked paste particles. The melt, leaking from the cracked particles, might either form new particles or enlarge the existing ones.

6 Conclusion Within this work it was shown that the explanation of void formation by the Kirkendall effect might be misleading since the classical experiment refers to solid diffusion only. However, the coagulation of small pores in liquids, forming voids, is termed as Kirkendall effect also. An exact differentiation is needed in this context. Additionally, explanations have been found in literature and have been assigned to void formation for the first time.

A decrease in density of $\mathrm{Al}$ with increasing temperature, corresponding to an increase in volume, was elaborated as crucial factor during contact formation process of PERC solar cells. This "volume effect" depends on temperature and Si content in the melt. A higher Si content reduces the volume effect and thus the formation of voids can be reduced by adding $\mathrm{Si}$ to the Al paste.

The existence of voids demonstrates that the dissolved $\mathrm{Si}$ together with all the $\mathrm{Al}$ is located in the $\mathrm{Al}$ paste matrix, i.e. in the particles surrounded by an $\mathrm{AlO}_{x}$ shell, except the part of each element found in $\beta$-Si, eutectic and $\alpha-\mathrm{Al}$.

However, according to the $\mathrm{Al} / \mathrm{Si}$ phase diagram, no significant amount of $\mathrm{Al}$ can be found in the local BSF $(\beta-\mathrm{Si})$. EDX measurements on partially filled contacts confirm that neither in the $\alpha$-Al nor in the thin layer located beneath the $\mathrm{Al}$ paste matrix a sufficient number of $\mathrm{Al}$ or $\mathrm{Si}$ atoms is incorporated to explain the void formation. Hence, the established assumption of a constant volume of paste particles has to be questioned.

Based on these results a new working hypothesis concerning void formation is elaborated. Void formation requires a spatial expansion of the paste particles to take up the missing material from the local contact area. If the expansion is restricted by the thin surrounding oxide layer around the particles, or the oxide shell contain defects, a burst of paste particles is assumed, involving a leak of the melt and, e.g., the formation of new paste particles as already shown in other studies.

In conclusion, the occurrence of voids can only be fully avoided by adding so much Si to the Al-paste particles that the "volume effect" does not come into play. On the other hand, a high amount of $\mathrm{Si}(>12 \%)$ will lead to a significant increase of paste resistivity. Hence, a reasonable compromise has to be found.

Acknowledgements The authors would like to thank J. Engelhardt, A. Herguth, L. Mahlstaedt, F. Mutter and B. Rettenmaier for their support. The financial support for parts of this work by the German Ministry of Economic Affairs and Energy under contract FKZ 0325581 is gratefully acknowledged.

\section{References}

[1] A. W. Blakers, A. Wang, A. M. Mine, J. Zhao, and M. A. Green, Appl. Phys. Lett. 55, 1363 (1989).

[2] E. Urrejola, K. Peter, H. Plagwitz, and G. Schubert, Appl. Phys. Lett. 98, 153508 (2011).

[3] E. Urrejola, K. Peter, H. Plagwitz, and G. Schubert, J. Appl. Phys. 107, 124516 (2010).

[4] T. Lauermann, A. Zuschlag, S. Scholz, G. Hahn, and B. Terheiden, in: Proc. 26th EUPVSEC, Hamburg, Germany (WIP, Munich, 2011), pp. 1137-1143.

[5] M. Bähr, G. Heinrich, O. Doll, I. Köhler, C. Maier, and A. Lawerenz, in: Proc. 26th EU PVSEC, Hamburg, Germany (WIP, Munich, 2011), pp. 1203-1209. 
[6] M. Rauer, C. Schmiga, R. Woehl, K. Rühle, M. Hermle, M. Hörteis, D. Biro, and S. W. Glunz, IEEE. J. Photovolt. 1, $22(2011)$.

[7] J. Müller, S. Gatz, K. Bothe, and R. Brendel, in: Proc. 38th IEEE PVSC, Austin, USA, 2012, pp. 2223-2228.

[8] J. K. Wijekoon, H. Khatri, D. Tanner, L. Zhang, A. Shaikh, and H. Ponnekanti, in: Proc. 27th EU PVSEC, Frankfurt, Germany (WIP, Munich, 2012), pp. 608-613.

[9] M. Rauer, R. Woehl, C. Schmiga, M. Hermle, M. Hörteis, and D. Biro, IEEE Electron Device Lett. 32, 916 (2011).

[10] M. Balucani, L. Serenelli, K. Kholostov, P. Nenzi, M. Miliciani, F. Mura, M. Izzi, and M. Tucci, Energy Procedia 43, 100 (2013).

[11] K. Dressler, M. Kratt, P. Voss, S. Riegel, A. Herguth, and G. Hahn, IEEE. J. Photovolt. 6, 63 (2016).

[12] Z. R. Du, N. Palina, J. Chen, F. Lin, M. H. Hong, and B. Hoex, in: Proc. 27th EU PVSEC, Frankfurt, Germany (WIP, Munich, 2012), pp. 1230-1233.

[13] B. Fischer, Diploma thesis, Australian National University Canberra and University of Applied Science RavensburgWeingarten, 1994.

[14] J. Müller, Ph.D. thesis, University Hannover, 2013.

[15] J. Schmitz, B. M. Hallstedt, J. Brillo, I. Egry, and M. Schick, J. Mater. Sci. 47, 3706 (2012).

[16] G. A. Storaska and J. M. Howe, Mater. Sci. Eng. A 368, 183 (2004).

[17] J. L. Murray and A. J. McAlister, Bull. Alloy Phase Diagrams 5, 74 (1984).
[18] E. Urrejola, Ph.D. thesis, University Konstanz, 2012.

[19] T. Lauermann, Ph.D. thesis, University Konstanz, 2013.

[20] M. Rauer, Ph.D. thesis, University Konstanz, 2014.

[21] A. D. Smigelkas and E. O. Kirkendall, Trans. Met. Soc. AIME 171, 130 (1947).

[22] L. Anestiev, L. Froyen, and L. van Vugt, J. Mater. Sci. 37, 1907 (2002).

[23] A. A. Zjuhovitskij and L. L. Schwarzman, Physical Chemistry (Metallurgija Publ., Moscow, 1976) (in Russian).

[24] F. Huster, in: Proc. 20th EUPVSEC, Barcelona, Spain, 2005, pp. 1466-1469.

[25] A. Uruena, J. John, G. Beaucarne, P. Choulat, P. Eyebeb, and G. Agestonelli, in: Proc. 24th EUPVSEC, Hamburg, Germany (WIP, 2009), pp. 1483-1486.

[26] F. S. Grasso, L. Gautero, J. Rentsch, R. Preu, and R. Lanzafame, in: Proc. 2nd Workshop on Metallization, Konstanz, Germany, 2010, pp. 15-21.

[27] S. Großer, M. Werner, and C. Hagendorf, Energy Procedia 77, 701 (2015).

[28] R. Horbelt, A. Herguth, G. Hahn, R. Job, and B. Terheiden in: Proc. 29th EUPVSEC, Amsterdam, Netherland, 2014, pp. 427-432.

[29] T. Lauermann, B. Fröhlich, G. Hahn, and B. Terheiden, Prog. Photovolt.: Res. Appl. 23, 10 (2013).

[30] E. Urrejola, K. Peter, H. Plagwitz, and G. Schubert, Appl. Phys. Lett. 98, 153508 (2011). 